\title{
Dolicy statement of the American Meteorological Society on tornado detection, Iracking, and warning
}

\author{
As adopted by the Council on January 27, 1980
}

\section{Introduction}

Alerting and warning the public to the existence of tornadoes involves problems of reliable detection, prompt reporting, and instant response. A tornado "watch" is issued to alert the public to the possibility that tornadoes may develop in a specific area within a specific time interval. It is a forecast issued in advance of tornado formation. A tornado "warning" is issued only after a storm, known or suspected to include a tornado, has been identified. It warns of a high probability of imminent danger. Instant response in warning situations requires the active participation of responsible meteorologists in both the private and public sector. This response can be achieved only by educational programs prior to the tornado season and rests upon public trust of the meteorologists' ability as demonstrated year round.

Considering detection and warning, it is important to understand some tornado "facts of life." First, the tornado is a small-scale by-product of its parent thunderstorm. Fortunately, less than $1 \%$ of thunderstorms produce tornadoes. Nevertheless, many such storms must be monitored as potential tornado producers. Second, of 700-1200 tornadoes in the United States each year, over half are comparatively weak and short-lived. These small tornadoes have only one to three minute lifetimes and paths less than a mile in length and 100 yards wide. Typical wind speeds are of the order of $100 \mathrm{mph}$. The exceedingly short life cycle of such tornadoes makes issuing timely warnings nearly impossible. With increasing population densities, even such weak tornadoes can be a significant threat.

On the other end of the tornado spectrum are the infrequent, devastating, and often long-lived violent tornadoes. Although large tornadoes comprise only $1-5 \%$ of reported tornadoes, they account for nearly $70 \%$ of tornado injuries and deaths and for the majority of total damage. Such tornadoes may exist over three hours, producing an essentially continuous damage path more than 100 miles long and hundreds of yards wide. Maximum wind speeds estimated from tornado damage analyses range upward to $300 \mathrm{mph}$, but reliable actual wind speed measurements are lacking.

\section{Tornado detection and tracking}

Weather radar continues to be the primary tool in detecting and monitoring potentially severe thunderstorms, including tornado-bearing storms. The presence of a well-developed "hook-shaped" or "figure 6" configuration within or on the boundary of the thunderstorm echo may indicate the existence of an organized region of within-storm rotation and tornado potential. However, many tornado-bearing storms do not have such clear-cut signatures and some storms give false echo signatures. Thus, prompt visual sightings still provide the most reliable indication of the presence of a tornado. Law enforcement officials, trained volunteer storm spotter networks, and the alert public form the principal, indispensable source of visual sighting and reporting. Training and educational programs for such storm spotting and reporting groups should be expanded. Additionally, members of the meteorological community at large should endeavor to provide reliable, professional observations to the responsible agency whenever possible.

Once a particular thunderstorm has been identified as a tornado-producer, it must be monitored and tracked for its entire lifetime. Not uncommonly, a single parent thunderstorm produces a sequence of several tornadoes over two or more hours and over distances of 100 miles or more.

\section{Detection system development}

Steady improvements continue to be made in the National Weather Radar Network by the addition of modern radars to replace obsolete systems and to fill gaps in the network. Numerous private radars have been acquired by media and consulting groups during the past decade, providing additional radar data sources near population centers. Nevertheless, these additional radars alone are unlikely to provide fully reliable tornado detection.

There are, however, three promising developments that offer hope for significant advances within the 
next few years. These are: 1) improved radar displays and interpretive techniques, 2) Doppler radar, and 3) satellite surveillance.

\section{Radar displays and processing}

Conventional weather radar displays can be improved using minicomputers and associated memory capabilities to reveal the 3-dimensional distribution of hydrometeors, thereby permitting better qualitative estimates of storm structure and updraft strength. The real-time analysis of these data would provide digital displays of the radar characteristics of storms, and could be designed to maintain a history of echo systems. Additionally, weather radar can be modified to provide colored, time-lapse sequences of echoes and their associated intensities. Such a modification aids in the detection of cyclonically rotating storms or portions of storms, mesoscale circulations, and storm movement. Further, technological developments are leading to superposition and display of both radar and satellite storm images.

\section{Doppler radar}

Unlike conventional weather radar, Doppler radar measures the speeds of raindrops in a storm, both toward and away from the radar; that is, in a radial direction. Economical improved measurement techniques recently have made it possible to provide graphic displays of Doppler velocity values in real time. During the past decade, measurements in severe thunderstorms have revealed the presence of tornadic vortex signatures as well as signatures of the tornado's parent circulation. Using these, an operational test of Doppler radar has been conducted. Its main advantages are increased warning lead times and reduced false alarm rates for tornadoes and severe thunderstorms, and an improved probability of detection. Based on these encouraging results, Doppler radar capability should be included in the next generation of weather radars.

\section{Satellite surveillance}

Two operational geostationary satellites positioned above the equator at $75^{\circ} \mathrm{W}$ and $135^{\circ} \mathrm{W}$ longitude provide 24-hour surveillance of severe weather systems over the U.S. The satellite infrared (IR) and visible data allow the estimation of thunderstorm intensity and thereby aid in the detection of severe thunderstorms. However, the most positive results appear to require short-interval ( $\leq 3$ minute) data to observe rapidly changing convective systems adequately. These high frequency data are not currently available for operations. Current operational data, at 30-minute intervals (in special cases, 15 minutes), can be used to outline areas of intense convection and possibly to detect new points of initial convection as indicated by the intersection of low-level thunderstorm outflow boundaries and other cloud lines, denoting concentrated convergence.

It is hoped that better IR spatial resolution $(\sim 1 \mathrm{~km})$, better vertical IR temperature resolution $(\sim 0.5 \mathrm{~K})$ and adequate time resolution ( $\leq 2$ minutes) for the analysis of rapidly changing thunderstorms will be available from the next generation of geosynchronous satellites.

In the early 1980 s, the first sounding equipment, the $V$ isible-Infrared Spin Scan Radiometer $A$ tmospheric Sounder (VAS), will be launched on a geostationary satellite. This new capability has the potential to lead to advances in the understanding and diagnosis of the dynamic processes responsible for severe thunderstorm development by providing high resolution (temporal and spatial) information on temperature and moisture.

\section{Related efforts}

Since about 1950 various investigators have suggested that tornado-producing thunderstorms emit radio frequency signals (sferics) of a character different from that of ordinary storms. Evaluation of such systems has been disappointing because no unique radio signature has been discovered. Present techniques yield an unacceptable number of "false alarms."

Over the long term, basic research should clarify medium-scale (mesoscale) meteorological processes that initiate and maintain severe storms, leading to further significant improvements in our ability to predict the place and time of storm events. Ongoing programs should be initiated within weather offices to enable forecasters to implement most effectively new concepts and technological advances in tornado formation, detection, and tracking. Further, academic institutions should include the diagnosis and short-term prediction of mesoscale events in their meteorological curriculum.

\section{Communications}

Distribution and broadcasting of tornado warnings varies markedly from one part of the country to the next, and sometimes from one county to another. There are diverse community interests, resources, and communication capabilities. Development of local communication and siren systems effectively disseminating storm warnings to a large and informed general public depends on the initiative and cooperation of many groups, including the National Oceanic and Atmospheric Administration (NOAA) and the Federal 
Emergency Management Agency (FEMA). A uniform national warning communication system is not on the horizon; thus, initiation of effective communications alerting systems involves cooperative effort among local offices of the National Weather Service (NWS), private meteorologists, local police, fire, civilian defense agencies, and radio and TV stations. A prepared and concerned public can do much to promulgate such efforts and to take necessary precautions when tornado warnings are broadcast.

An effective warning system must be timely. Impor- tant developments in this regard include: 1) new and faster methods of data handling and forecast (warning) dissemination, such as the NWS's Automation of Field Operations and Services (AFOS) system, and 2) the direct and rapid delivery of tornado warnings to users through NOAA Weather Radio (NWR). Future progress in improved reliable warnings and their dissemination will involve sustained research and development activity, together with economic, sociological, and political dedication to create improved solutions.

\title{
policy slatement of the American Meteorological Sociely on mobile homes and severe windstorms
}

\author{
As adopted by the Council on January 27, 1980
}

Mobile home living is becoming a way of life for a significant proportion of the population of the United States. Over ten million people permanently reside in over four million mobile homes throughout the country. Additionally, another one million mobile homes are occupied on a part-time basis.

It is with grave concern that the American Meteorological Society observes that almost 100000 mobile homes ( $\sim 2 \%$ of all mobile homes) are damaged each year by windstorms to the extent that insurance claims are filed. Further, the flying debris produced by unsecured mobile homes during windstorms of ten inflicts damage to surrounding equipment and permanent buildings, thus compounding the problem.

Hurricanes and tornadoes are not the only windstorms that destroy mobile homes. Often strong, short-lived gusty winds from severe thunderstorms or "dry" thunderstorms cause major damage and destruction to mobile homes. Wind gusts from such storms are frequently greater than the $60 \mathrm{mph}$ damage threshold for these structures. Such storms occur in all parts of the country, but are especially numerous in the High Plains and western states. Additionally, near scenic foothills and mountain areas, severe downslope windstorms, lasting six hours or more, can batter structures with wind gusts up to $120 \mathrm{mph}$. These windstorms of ten affect areas in a 15-30 mile wide band for 100 miles along a mountain range.

Death and destruction in the wake of tornadoes, hurricanes, thunderstorm gusts, and downslope mountain winds have prompted efforts to encourage owners of large mobile home parks to construct shelters. Such activity is considered essential for life-safety. Also, efforts at the local level to develop regulations governing tie-downs have proven effective as a property protection measure in wind-prone areas.

Recommendations: The American Meteorological Society urges mobile home residents to vacate their dwellings and to go immediately to a designated storm shelter when a severe weather warning for high winds is in effect. The Society also suggests that adequate shelters be constructed at large mobile home parks as a precaution against personal injury and death. Local civil defense officials have access to plans for such shelters published by the Federal Emergency Management Agency.

As a property protection measure, the Society urges that mobile homes be properly anchored to the ground. Information on proper mobile home tie-downs and shelters may be obtained from government sources through the nearest State Division of Emergency Services (Civil Defense) or corporations specializing in mobile home tie-down equipment and installation. 


\section{Control Data: Committed to}

\section{Control Data people, systems and services are helping to bring about more accurate weather forecasting in the ' 80 's.}

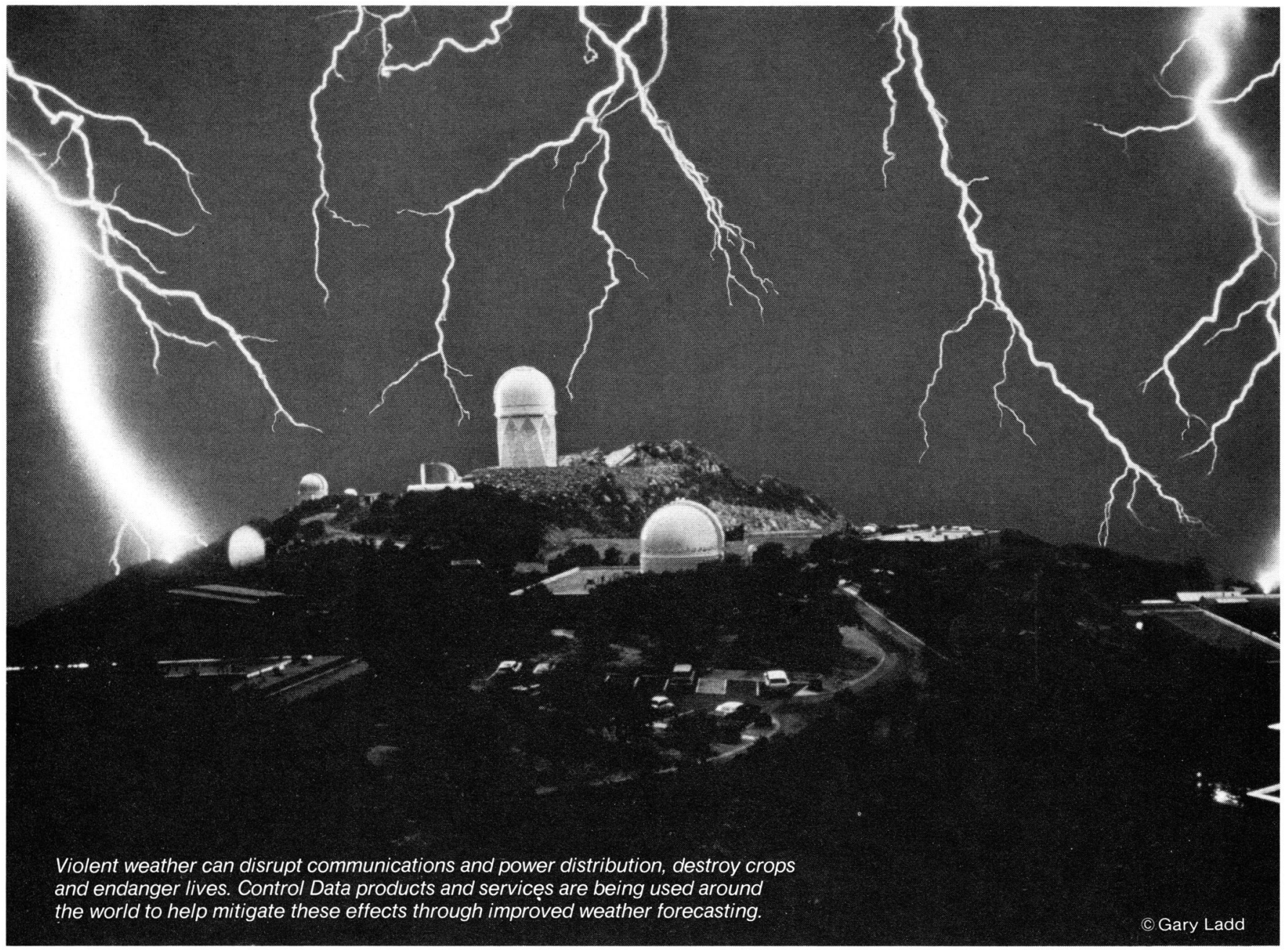

Man's ability to more accurately predict the weather closely parallels the development of the superscale computer. The numerical methods needed to forecast the weather were developed in 1946, but the first useful computer-aided forecasts were not processed until 1955. In 1960, the U.S. Navy began processing state-of-the-art numerical prediction models, using a $\mathrm{CDC}^{\circledR} 1604$, Serial 1 - the first product of Control Data Corporation.

In twenty years we've become an acknowledged leader in supplying large-scale computers to major weather centers all over the world. Our recently announced CYBER 170 Series 700 systems continue this tradition by offering increased performance at reduced cost. And our CYBER 200 Series represents the latest in state-of-the-art computer design, by performing up to 100 million operations per second through vector stream processing and large-scale integrated (LSI) technology.

\section{Control Data's commit-} ment goes far beyond large-scale processors

We're also known for our weather data communications capabilities. Our widely accepted Message Switch System uses CDC CYBER 18 computer systems and is designed specifically for receiving and transmitting meteorological data. Properly configured, the Message Switch System provides plotting capabilities which can be used to produce upper air charts and soundings, surface weather, grid-to-isoline and other plotted information.

Through our AGSERV crop weather forecasting service, we help meet the critical need for more accurate crop production 


\section{the Environmental Industry}

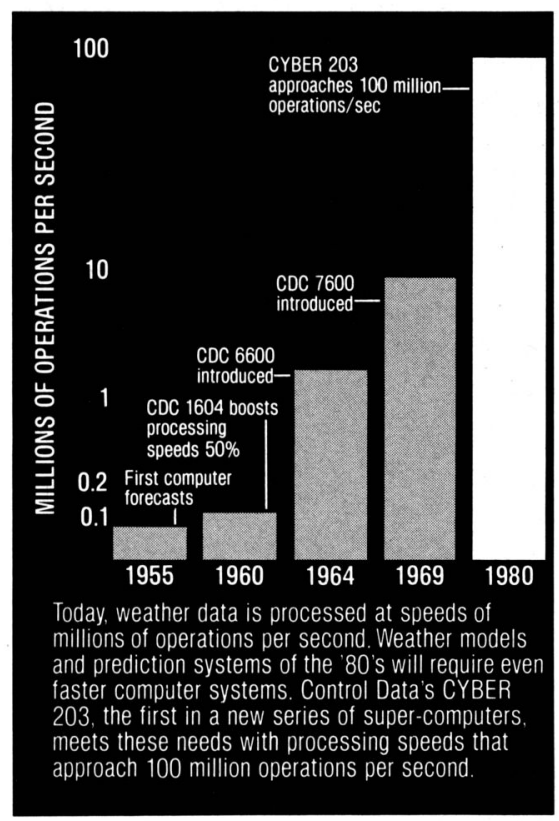

predictions. The service is available through Control Data's worldwide data services networks or as software on our CYBER 170 computer systems. The AGSERV system uses a sophisticated agricultural data base, statistical programs and crop modeling techniques to produce daily largearea crop production potentials.

Through our Environmental Consulting Services, we provide the expertise to support our products and services as well as a whole range of capabilities from basic research to the application of state-of-the-art computer technology to specific environmental problems.

Global Weather Dynamics, Inc. (GWDI), a wholly owned subsidiary of Ocean Data Systems, Inc. (ODSI) of Rockville, Maryland, was established as part of a cooperative program between Control Data and ODSI. Using Control Data systems, software and CYBERNET ${ }^{\circledR}$ data processing services, GWDI provides specialized weather and oceano graphic forecasting services for companies, construction firms, utilities and agriculture. Capabilities range from climatic studies on a national or global scale to detailed short-range forecasts for specific areas.

\section{Control Data is a single source for solutions to your problems}

Control Data is more than a computer company. We provide our customers in the environmental industry with a wide range of support. We provide training in both the environmental and data processing fields to keep our customers in the forefront of the latest technology and practices. Our staff includes professional engineers, financial consultants, systems analysts and meteorologists. They're helping our customers find solutions to their individual problems.

Systems. Services. Solutions. Measures of Control Data's commitment to the environmental industry.

For more information, contact:

Control Data Corporation

Environmental Industry Marketing HQW09A

P.O. Box 0

Minneapolis, MN 55440
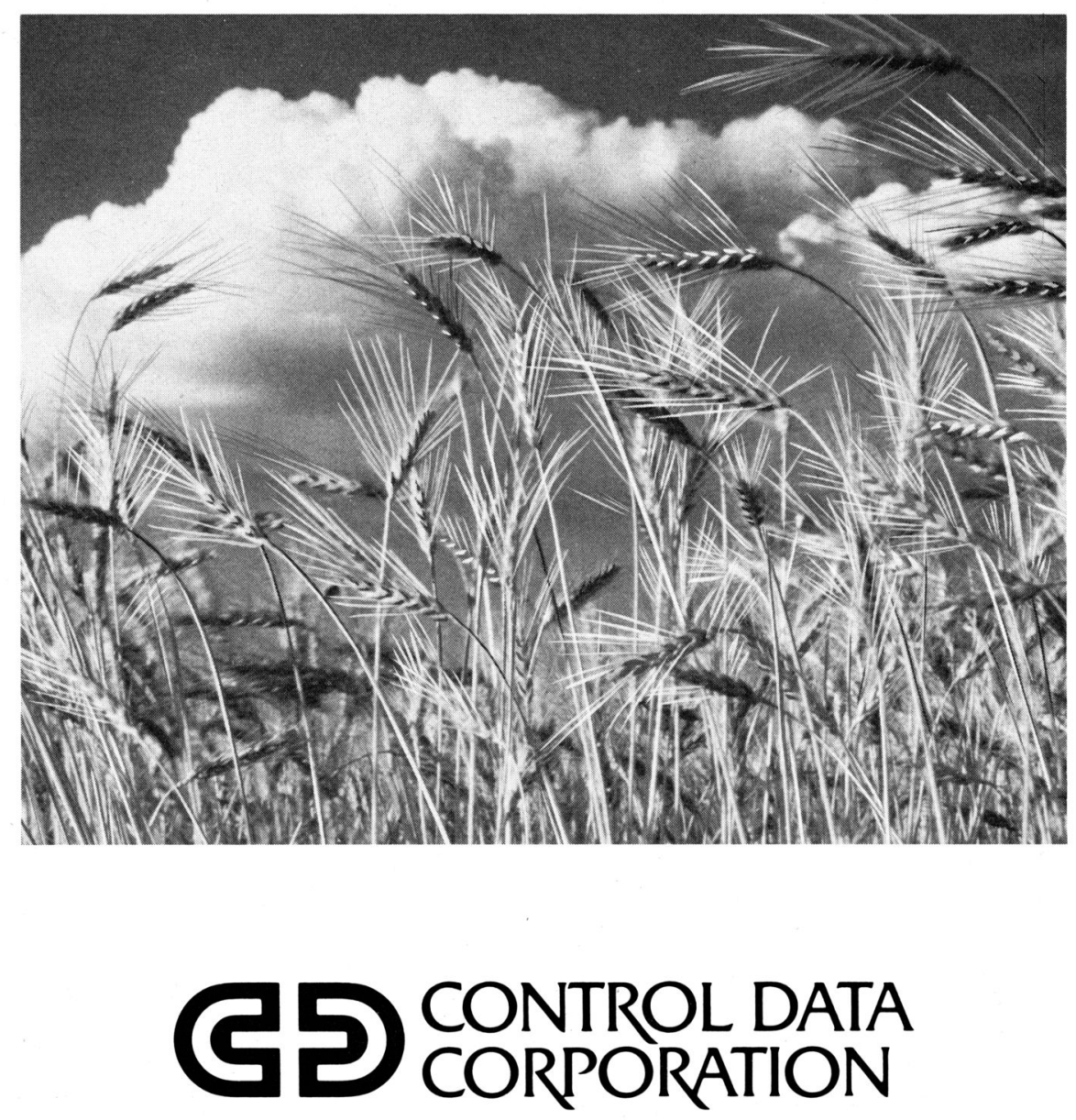
announcements continued from page 347

\section{New journal on the environment}

The Environmental Professional (EP), a new quarterly publication of the National Association of Environmental Professionals (NAEP), may be of interest to some Bulletin readers. The journal aims "to provide an open forum, for NAEP members and other concerned individuals, for the discussion and analysis of significant environmental issues." The journal is intended to serve as a "timely and single comprehensive outlet" for the publication of interdisciplinary findings aimed at exploring and resolving environmental problems that often cut across disciplinary and man-made boundaries.

Due to the nature of contemporary environmental concerns and the diversity of NAEP membership, articles that have substantial interdisciplinary content are given priority for publication. (Articles published in the first issue of $E P$, which appeared in 1979, included: World Carbon Dioxide Problems; Encouraging the Installation of Pollution Control Equipment: The Use of Automatic Adjustment Clauses; A Brief Look at Florida's Environmental Heritage; and Federal State Cooperation in Nuclear Power Plant Licensing: A Review of Roles and Environmental Issues. Part 1 of a Series). Normally, reports of findings that go beyond a laboratory analysis, a field experiment, or a theoretical derivation and further discuss the ramifications of implementation-in public, governmental, industrial, or educational situations-are considered appropriate for the journal. In particular, studies linking scientific, technologic, and socioeconomic systems to effective impact assessments, regulation, and environmental protection are most welcome. In general, articles in $E P$ will include those that attempt to capture and analyze the issues that occur at the interface of environmental science, technology, education, economics, sociology, administration, management, planning, law, and policy.

For the NAEP membership and the public, the journal will carry association news, chapter news, and brief sketches of representative professional activities of members. It will encourage timely discussion of the needs of the profession together with those of the programs of NAEP. Periodically, the journal will devote its pages to selected topics of special concern to a significant segment of the NAEP membership.

The annual subscription rate for $E P$ is $\$ 35.00$; the two-year rate is $\$ 66.50$. Prices include surface postage and insurance; air mail subscriptions are extra. The journal is available from: Pergamon Press, Maxwell House, Fairview Park, Elmsford, N.Y. 10523.

For information on membership rates in NAEP, contact: National Association of Environmental Professionals, P.O. Box 1223, Alexandria, Va. 22313.

Continued on page 401

bringing science into the

\section{AGROMETEOROLOGY}

J. SEEMANN, Heusenstamm, Federal Republic of Germany, Y.I. CHIRKOV, Moscow Agricultural Academy, J. LOMAS, Meteorological Service, Bet-Dagan, Israel, and B. PRIMAULT, Swiss Institute of Meteorology, Zurich

Agrometeorology is the first comprehensive treatise to provide basic information on the many areas of meteorology applied to agriculture. It offers new insights into the physical basis of meteorological energy turnover, as well as discussing the more efficient uses of climatic resources to increase world-wide agricultural production.

$1979 / 324$ pp./89 illus./ 61 tables/cloth $\$ 53.90$ ISBN 0-387-09331-1

\section{ENVIRONMENTAL INSTRUMENTATION}

LEO J. FRITSCHEN, University of Washington, Seattle, and LLOYD W. GAY, University of Arizona, Tucson

This volume presents the necessary information for acquiring a unified and sys-

tematic overview of environmental measurement fundamentals, the basics of energy transfer, and OCC circuitry. Following this are many thorough discussions on the measurement of temperature, heat flow, radiation, humidity, wind speed, and pressure. Data acquisition, signal recognition, and noise are also examined. Anyone interested in the relationship of biological organisms and meteorology will want to read this book. $1979 / 216 \mathrm{pp}$./ 66 illus./cloth $\$ 22.80$ (Springer Advanced texts in Life Sciences) ISBN 0-387-90411-5

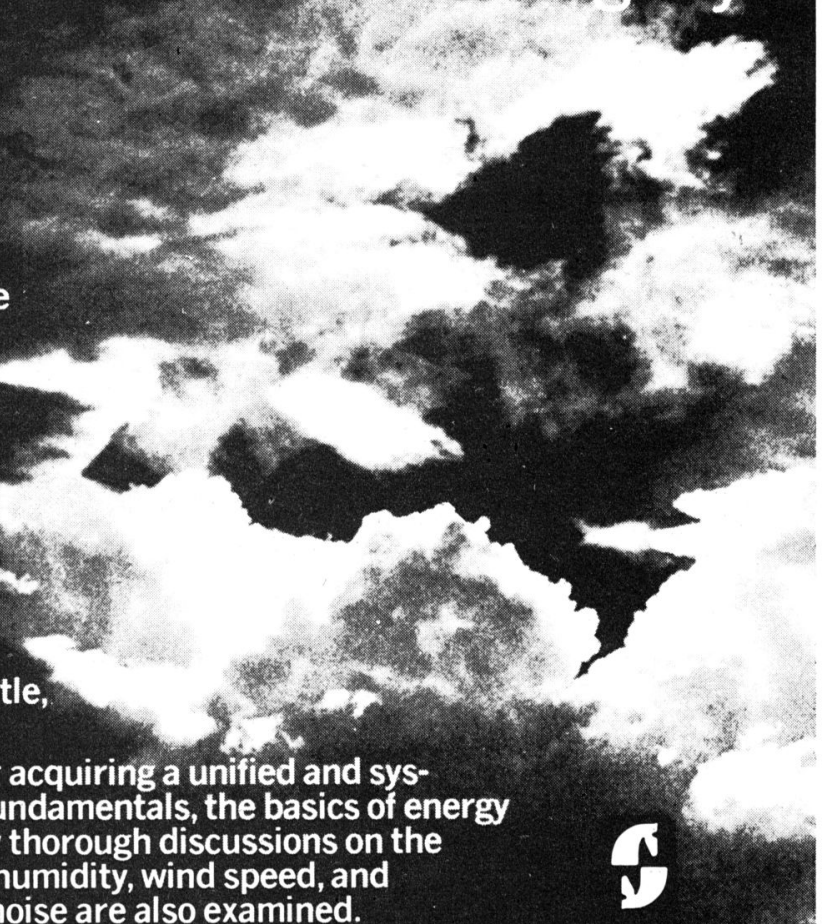

